\title{
A (des)estabilização das redes sociais e o impacto na saúde do professor universitário: o caso português
}

\author{
Social networks (in)stability and its impacts on higher \\ education teachers health: the portuguese case
}

\author{
Patricia Passos Sampaio ${ }^{1}$, José Manuel Peixoto Caldas 2,3,4,
}

Ana Maria Fontenelle Catrib,

\begin{abstract}
Resumo
Este estudo se propõe analisar o impacto das redes sociais na saúde do professor do ensino superior em Portugal. A adesão ao Processo de Bolonha exigiu uma reestruturação do ensino superior e uma ressignificação do papel docente. A prática de avaliação individual e a estruturação da carreira em pirâmide estimularam a competitividade entre os professores, minando a cooperação e a dinâmica do reconhecimento e fragilizando as redes entre pares. Por meio de entrevistas semiestruturas, identificamos as percepções e as visões dos docentes como atores diretamente envolvidos em redes educacionais. A análise das falas aponta que eles têm buscado apoio e segurança emocionais na família, nos amigos fora do trabalho e em pares de outros departamentos, em experiências exitosas de cooperação em rede - fato que tem viabilizado a construção e a manutenção de laços sociais geradores de saúde, interação, solidariedade, bem-estar e qualidade de vida, além de redes sociais com caráter preventivo e de promoção de saúde.
\end{abstract}

Palavras-chave: redes sociais; capital social; professor; psicodinâmica do reconhecimento; promoção de saúde.

\section{Abstract}

This study aims to analyze the impact of social networks on higher education teachers' health in Portugal. The accession to the Bologna process demanded the restructuring of higher education, giving a new meaning to the teacher's role. The practice of individual evaluation and structuring of a pyramid career stimulated the competition among teachers undermining the cooperation and recognition dynamics also weakening the networks betweens pairs. Using semi structured interviews, we were able to identify their perception and views as protagonists who are directly involved in educational networks. The analysis of the teachers' speech show that they have been seeking for support and emotional security in their families, friends outside of work and in pairs from other departments with successful experiences in network cooperation. This fact has enabled the construction and maintenance of social bonds that generate health, interaction, sympathy, well being and quality of life; social networks with preventive and health promoting aspects.

Keywords: social network; social capital; teacher; psychodynamics of recognition; health promotion.

\footnotetext{
${ }_{1}^{1}$ Professora Mestre em Psicologia da Universidade de Fortaleza (UNIFOR) - Fortaleza (CE), Brasil.

2 Pós-Doutor em Antropologia pela Universitat de Barcelona (UB) - Barcelona, Espanha.

${ }^{3}$ Professor Visitante do Departamento de Psicologia Clínica do Instituto de Psicologia da Universidade de São Paulo (USP) - São Paulo (SP), Brasil.

${ }^{4}$ Pesquisador Sênior da Fundação de Amparo à Pesquisa do Estado de São Paulo (FAPESP) - São Paulo (SP), Brasil.

${ }^{5}$ Pós-Doutora em Saúde Coletiva pela Universidade Estadual de Campinas (UNICAMP) - Campinas (SP), Brasil.

${ }_{6}^{6}$ Professora Titular do Mestrado e Doutorado em Saúde Coletiva da Universidade de Fortaleza (UNIFOR) - Fortaleza (CE), Brasil.

Trabalho realizado em Portugal.

Endereço para correspondência: Patricia Passos Sampaio - Av. Washington Soares, 1321, Bairro Edson Queiroz - CEP 60811-905 - Fortaleza (CE), Brasil Email: patriciap@unifor.br

Fonte de financiamento: nenhuma.

Conflito de interesses: nada a declarar.
} 


\section{INTRODUÇÃO}

Este estudo se propõe analisar o impacto das redes sociais na organização do trabalho docente e saúde do professor no contexto do ensino superior português.

Sabemos, a partir das contribuições de Bourdieu ${ }^{1}$ que “[...] a ciência é um campo social, como outro qualquer, com suas relações de força e monopólios, lutas e estratégias, interesse e lucros [...]". (p. 112) ${ }^{1}$ Nesse sentido, nenhuma prática científica se faz de forma "desinteressada"; o campo é mais do que uma área de conhecimento e é compreendido também em uma dimensão política ${ }^{2}$. Na América Latina, a discussão crítica da Saúde Pública e a problematização da abordagem biomédica sobre o processo de saúde-doença viabilizaram o desenvolvimento da Saúde Coletiva, campo de confluência da Epidemiologia, Ciências Sociais em Saúde, Planejamento e Avaliação de Serviços de Saúde ${ }^{3}$.

O trabalho em Saúde Coletiva "[...] é um conjunto de atividades eticamente comprometidas com seu objeto - as necessidades sociais de saúde com vistas à [...] promoção, proteção, comunicação e educação em saúde" (p. 106)4. Esta investigação se situa no campo da Saúde do Trabalhador tal como pensada pela Saúde Coletiva - um campo de saber e um âmbito de práticas comprometidas e politicamente situadas.

Os seres humanos estão ligados entre si e com organizações, influenciando-se mutuamente e sendo influenciados. Essa interação ocorre em diferentes espaços (concretos e virtuais) a fim de satisfazer demandas e necessidades de ordem pessoal, social e organizacional, o que pode ser um fator determinante de sofrimento psíquico e posterior adoecimento, caso não sejam tomadas as medidas adequadas à proteção e à promoção da saúde do docente.

A configuração em redes é algo inerente ao humano; ele vai se agrupando e estabelecendo relações de amizade, no trabalho e na família; são, portanto, fenômenos coletivos que viabilizam a gestão das políticas sociais e otimizam a utilização dos recursos disponíveis ${ }^{5}$.

Redes sociais referem-se a um conjunto de relações entre indivíduos, grupos e organizações ${ }^{6}$. Redes "[...] são sistemas complexos, compostos por agentes que estabelecem diversos tipos de relações" (p. 331)7. A teoria das redes:

[...] tenta responder simultaneamente a duas ambições: explicar o comportamento dos indivíduos através das redes em que eles se inserem e explicar a estruturação das redes a partir da análise das interações entre os indivíduos e suas motivações (p. 8) . $^{8}$.

Trata-se de um excelente modelo para explicar as influências mútuas entre indivíduos e sociedade a partir dos vínculos e laços estabelecidos entre eles; além de permitir “[...] analisar o espaço relacional, os seus movimentos e o conteúdo desses movimentos - a forma e o conteúdo da relação simultaneamente" (p. 9) $)^{8}$.
As redes viabilizam trocas de afetos, aprendizagens, cooperação, reconhecimento e suporte à ação, apoio e segurança a partir das ramificações e da interdependência construída. Essas trocas só são possíveis a partir do capital social desse grupo:

\footnotetext{
O capital social é o conjunto de recursos atuais ou potenciais que estão ligados à posse de uma rede durável de relações mais ou menos institucionalizadas de interconhecimento e de interreconhecimento ou, em outros termos, à vinculação a um grupo, como conjunto de agentes que não somente são dotados de propriedades comuns (passíveis de serem percebidas pelo observador, pelos outros ou por eles mesmos), mas também são unidos por ligações permanentes e úteis (p. 67) ${ }^{9}$.
}

A rede social é, pois, um lugar de interações e de construção do capital social. Estar ancorado em uma rede implica em negociações e em obrigações, mas também em uma série de valores compartilhados: confiança, sociabilidade, solidariedade, amizade, respeito, criatividade, cooperação, reciprocidade, proatividade, simpatia. Tais valores subsidiam a associação voluntária a partir da horizontalização do poder, da interação sistemática, das estratégias de interesse coletivo e da busca de cooperação para solucionar certos impasses que não se consegue individualmente ${ }^{5,10,11}$.

\section{O ENSINO SUPERIOR NA CONTEMPORANEIDADE}

O cenário do ensino superior é de

[...] internacionalização dos sistemas educativos; mundialização das suas políticas, massificação do ensino e empresarialização do domínio educativo, [...] acentuando a importância da educação para a competitividade econômica nacional num mercado cada vez mais global (p. 17) ${ }^{12}$.

A lógica neoliberal de mercado invadiu o ensino superior, fato que alterou sobremaneira o papel do Estado, que passou a desinvestir financeiramente no ensino superior e assumiu um papel de avaliador e de regulador das políticas educacionais ${ }^{13}$.

Em um panorama de incertezas, diversidade, pluralidade e instabilidade, a realidade se apresenta como uma teia complexa de ligações. Qual é o lugar do docente nessa teia de intensificação e de precarização do trabalho?

A lógica gerencialista que invadiu o ensino superior traz consigo a lógica da avaliação individual do desempenho. Esta cria a concorrência, mina a solidariedade, desestabiliza a psicodinâmica do reconhecimento e compromete o clima organizacional - fatores comprometedores da saúde psíquica do trabalhador e que geram um efeito nefasto no "viver-junto". "No fim, cada qual se encontra só, no meio da multidão, em um ambiente humano e social com características de hostilidade" (p. 46) ${ }^{14}$.

\section{DOCÊNCIA SUPERIOR EM PORTUGAL}

O sistema português tem uma constituição binária: o ensino universitário (mais conceitual) e o ensino politécnico 
(mais pragmático). O objetivo do politécnico, com cursos de curta duração, é formar técnicos de nível superior que possam responder ao desenvolvimento regional ${ }^{15}$.

O ensino politécnico veio possibilitar a mudança de um ensino de elite para um ensino de massa, desviando os estudantes do ensino universitário. Trata-se de um ensino profissionalizante, que responde a uma demanda de mão de obra mais qualificada no nível técnico intermediário ${ }^{12}$.

A carreira do docente envolve: assistente, auxiliar, associado e catedrático. A progressão depende da abertura de vagas (morte ou aposentadoria) e é efetivada via concurso público. Trata-se de um sistema piramidal, que, por sua estrutura, estimula a competitividade ${ }^{12}$.

O ensino, a investigação, a extensão e a gestão compõem a atividade docente, no entanto a investigação é a atividade mais valorizada, fator que gera uma certa tensão entre os docentes.

A questão da qualidade no ensino entrou definitivamente na agenda das instituições europeias em resultado do Processo de Bolonha [...] paradoxalmente a atividade de ensino continua a ter um papel quase nulo na contratação e na carreira do docente as quais continuam a depender principalmente das atividades de investigação, uma investigação tendencialmente disciplinarizada, territorializada e competitiva à margem do ensino, ou mesmo à sua custa (p. 24) $)^{13}$.

A Fundação para Ciência e Tecnologia (entidade pública) avalia sistematicamente suas políticas educacionais e o fazer do professor de acordo com critérios de internacionalização: desvalorização de publicações na língua portuguesa e valorização de parcerias internacionais. Incentiva-se o desenvolvimento de projetos internacionais em detrimento da análise de indicadores relativos à relevância social e ao impacto local das investigações ${ }^{12,13,16}$.

Portugal aderiu ao Processo de Bolonha e está refletindo sobre os seus efeitos ${ }^{12,17}$. O Processo de Bolonha (1999) instituiu o Espaço Europeu de Educação Superior - tentativa de uniformização do espaço educacional - e visa tornar a Europa competitiva no mercado mundial a partir de dois eixos: desresponsabilização do Estado do financiamento e das políticas públicas e internacionalização das universidades ${ }^{12}$.

Trata-se de um modelo pautado na competitividade e regulado pelo mercado que apresenta as seguintes dimensões: adaptação às demandas produtivas; egressos aptos a responder as demandas do mercado; mercantilização da educação superior; reorganização do ciclo de estudo (mestrado integrado à graduação); homogeneização do sistema de créditos; mobilidade; sistema de avaliação feito em parceria com organismos nacionais e internacionais; regulação da educação pelo mercado / lógica do consumo; agenda transnacional; diminuição da participação dos atores universitários na tomada de decisão; busca de qualidade do ensino; lógica gerencialista; aprendizagem por competências; diminuição do tempo das licenciaturas ( $1^{\circ}$ ciclo).
[...] trata-se também de um movimento mais vasto de construção de novos sentidos para o ensino superior, radicado em mudanças profundas no papel que as universidades hoje desempenham, e que exigem uma reconfiguração da profissionalidade docente através da articulação entre ensino, investigação e desenvolvimento profissional (p. 5281) ${ }^{16}$.

Como consequência desse processo, o professor teve que reconfigurar seu papel, passando a ser um tutor que apoia e motiva o aluno, o qual torna-se o centro do processo ensino-aprendizagem. Cabe ao aluno montar o seu desenho de estudos de forma autônoma, cujo foco é aprender a aprender.

\section{METODOLOGIA}

Esta investigação foi feita a partir de uma abordagem qualitativa e, portanto, trata-se de uma pesquisa de natureza interpretativa-compreensiva ${ }^{2,18,19}$, que visa analisar a relação entre saúde e redes sociais a partir da perspectiva do professor.

A pós-graduação em Saúde Pública é um espaço de reflexão e de produção de pesquisas com vistas à promoção de saúde da população, daí a curiosidade em investigar como os professores desse campo vivenciam o seu próprio objeto de estudo no cotidiano.

Investigamos professores portugueses vinculados à Saúde Pública e à Educação, com o objetivo de conhecer o sistema educacional português. Foram entrevistados 15 docentes: 1 da Universidade de Coimbra, 4 da Universidade do Minho e 10 da Universidade do Porto.

$\mathrm{O}$ acesso à subjetividade do trabalhador é mais pertinente quando ele atribui parte das próprias significações ao seu trabalho. "A via de acesso à vivência subjetiva e intersubjetiva do trabalho, passa exclusivamente pela palavra dos trabalhadores [...]" (p. 142) ${ }^{20}$.

Os dados foram coletados por meio de entrevistas semiestruturadas, as quais continham questões abertas que permitiram ao entrevistado falar livremente sobre: o significado atribuído ao seu trabalho, desafios e dificuldades enfrentados no dia a dia, sentimentos em relação à docência, ao contexto de trabalho, impacto do trabalho sobre sua saúde, percepção do ambiente de trabalho (estrutura física e interações sociais).

Seguindo os princípios éticos que regem a pesquisa com seres humanos, esta investigação foi aprovada pelo Comitê de Ética da Universidade de Fortaleza (UNIFOR), no Ceará, sob n. 10.056 de 24/13/10. Os docentes dos departamentos de Educação e de Saúde Pública foram contatados por e-mail e foram entrevistados aqueles que espontaneamente responderam ao convite.

A análise das falas foi realizada por meio do modelo temático ${ }^{18}$ e seguiu os seguintes passos: codificação das falas; agrupamento das codificações em quatro categorias analíticas; seleção de falas representativas de cada categoria; articulação com as categorias teóricas (redes sociais, sofrimento psíquico, saúde coletiva). 


\section{RESULTADOS E DISCUSSÃO}

O depoimento dos professores aponta para um intenso sofrimento, acompanhado de adoecimento (enxaquecas, fibromialgia e câncer de mama). Uma estratégia frequente de enfrentamento ao ambiente hostil, não colaborativo, é o desenvolvimento de conexões com amigos e família e a participação em projetos de outros departamentos. Como já mencionamos anteriormente, a desarticulação de redes parciais tem o potencial de instaurar o sofrimento psíquico e o adoecimento.

As percepções dos professores foram agrupadas em quatro categorias analíticas:

1. A prática docente como uma rede: no contexto atual, os professores demonstram que sua atividade depende de uma série de conexões que são estabelecidas com alunos, pares, Estado, organismos internacionais e outras universidades.

Se sou professor [...] há uma prática de relação, comunicação [...]. $\hat{E}$ um trabalho que me obriga a ler, estudar [...]. É o meu trabalho, um espaço de relação e eu não vivo nos meus livros ou escritas, eu tenho que fazer ter sentido a minha relação com os alunos. (E-1)

Eu estou na investigação, então eu acabo por ter um conjunto de rituais, de construção da relação com associações internacionais, com investigadores de renome [...]. Só que esse processo de construção [...] não é um processo da pessoa sozinha. É um processo que é realizado pela pessoa no âmbito da comunidade de aprendizagem. (E-2)

Ao mesmo tempo em que percebem a docência como uma rede, eles apontam que o sistema educacional, da forma como está estruturado, não tem colaborado para a valorização dos laços sociais e sua dimensão simbólica ${ }^{21}$.

2. Interferência do sistema educacional na manutenção das redes: a forma piramidal de carreira favorece a desorganização de redes quando mina a cooperação e estimula a competitividade ${ }^{12,13}$. Se uma equipe é formada com professores de diferentes áreas, a pontuação de uma delas fica comprometida, o que desestimula a formação de grupos de investigação de áreas diferenciadas.

[...] essa linha [de pesquisa] era uma linha que tinha colega de vários departamentos aqui do instituto; [...] E começou a gerar um mal-estar porque as pessoas que estão à frente das linhas de investigação estão a sentir que deixavam seus trabalhos em seus departamentos. [...] e eu tive muitos sinais de que isso acontecia, muitas pessoas me disseram que não lhes era permitido vir para essa linha porque diminuía a pontuação lá. (E-4)

[...] é um problema que atravessa a vida da universidade em geral. [...] foi se desenvolvendo uma lógica que afastou os professores das relações de amizade, de fraternidade e companheirismo para relações de competição e, portanto, os laços, os afetos foram se perdendo, [...] o ambiente universitário é muito competitivo por força da organização da carreira, né? [...] não tem, na verdade, espaço para cooperações, cada um está sozinho. (E-1)

Estou aqui há 17 anos [...] a minha filha casou há 3 anos, e no casamento não foi um colega meu, então isso tem um significado. (E-2)
3. A diferença que as redes operam: as relações são percebidas pelos professores como indispensáveis e necessárias ao crescimento e desenvolvimento profissional e à inovação, tanto que, se o sistema desorganiza algumas formas de ligação, o coletivo encontra novas reconfigurações e reorganizações, como é o caso positivo do Instituto de Educação da Universidade do Minho.

O Instituto tem uma prática bem-sucedida a partir da formação e sedimentação de uma rede de colaboração a partir do projeto TPU (Transformar a Pedagogia na Universidade) $)^{13,16,22}$. Trata-se de uma atividade de reflexão e ação sobre a pedagogia na Universidade do Minho. A rede formou um grupo de trabalho em 2010 (GT-IP) e, em 2013, um Núcleo de Estudos e Inovação da Pedagogia (NEIP): espaço coletivo de reflexão, investigação e produção de conhecimento na área, bem como espaço de promoção de seminários, grupos de estudo e assessoria pedagógica para os demais departamentos da universidade.

"Várias atividades contribuíram para a constituição de uma rede de colaboração em torno da exploração da pedagogia" (p. 5298) ${ }^{22}$. O resultado é o desenvolvimento de uma cultura de colaboração, um projeto que se desenvolve em solo adverso, subvertendo o instituído em uma perspectiva emancipatória e de consolidação de redes de trabalho. Vejamos o depoimento de um dos integrantes do NEIP:

Em um trajeto que eu não imaginei que ia acontecer, ao redor da pedagogia na universidade, foram embarcando cada vez mais colegas de outras áreas no seio da educação. (E-4)

O relato a seguir é de uma professora que tem uma doença crônica e tem dificuldades em negociar, pois o clima é tenso. Quando necessário, ela faz a troca com docentes que são de outro departamento da universidade que não o seu.

[...] é difícil meus colegas entenderem que eu faço pesquisa com sofrimento. É difícil... por exemplo, estou em um Centro de Investigação que não pertence aqui, pertence à Filosofia, porque não conseguem entender, então decidi ir para um outro [...]. A relação não facilita quem está doente, fazer vínculos em outros grupos. Não temos bom ambiente acadêmico entre colegas. Meu grupo é o da ' $X$ ', mas a ' $X$ ' não faz parte do meu departamento e eu não posso trocar aulas com eles. A ' $Y$ ' não é do meu departamento, mas tem aulas antes ou depois de mim. O que faço é trocar com ela. (E-5)

4. Família e amigos como redes de suporte e apoio: diante da precariedade e da intensificação do trabalho, as relações com a família e amigos assumem um papel fundamental de apoio e de segurança emocionais, principalmente quando não é possível desenvolver amizade no local de trabalho ${ }^{10}$ :

Haja fluoxetina para ajudar, mas também outras coisas, né? Uma família, amigos, a família ajuda muito. (E-1)

[...] tenho um suporte social invejável, uma mãe e pai altamente disponível, uma tia que é solteira... que me dá todo apoio possível, além de sogros [...] se não tivesse o suporte social, não produziria o que produzo, tenho certeza absoluta, não só pelo tempo de trabalho efetivo, mas pela estabilidade emocional que esse complemento nos 
dá. Me permite estar perfeitamente concentrada e descansada [...] então, isso me deixa tranquila. (E-6)

As redes sociais primárias proporcionam essa tranquilidade a partir da construção de um espaço de confiança, que é tecido coletivamente. "Redes sociais só podem ser construídas com base na confiança mútua disseminada entre os indivíduos"10.

Outra perspectiva de análise das redes sociais é a partir do papel das dádivas ${ }^{21}$ e das relações interpessoais de solidariedade como forma de responder satisfatoriamente às necessidades e às demandas sociais dos indivíduos com vistas ao bem-estar. Ela se faz um questionamento que é muito pertinente, tendo em vista as falas apresentadas: como falar de generosidade em uma sociedade individualista, uma vez que a dádiva se alimenta da generosidade, liberdade e voluntariado? O que se quer demonstrar é que, quando o Estado falha, é possível resgatar o potencial da dádiva.

O conceito de redes sociais auxilia na compreensão de como o sujeito mobiliza formas de relações que viabilizam seu bem-estar. Ficou demonstrado que o professor tem consciência que seu trabalho depende de uma teia bem articulada de diferentes atores. No entanto, seu dia a dia inviabiliza essa tessitura.

Que tipo de apoio/suporte demandam? Com quem contar, além da família e amigos fora da universidade? Como desenvolver um sistema de dádiva nos colegiados? A estrutura atual não dificulta essa construção? O resgate de redes com os professores poderia seguir a sugestão: um resgate de redes parciais, que são “[...] conjuntos de laços que são ativados para dar resposta a este problema concreto" (p. 13) ${ }^{21}$.

A reconstrução de um cotidiano fragilizado ${ }^{23}$, que é, às vezes, até destruído pelo sofrimento psíquico, como é o caso dos docentes portugueses, só se torna possível por meio de campos de sociabilidade mais amplos, por meio de dispositivos de apoio e de solidariedade. Uma vez que nas sociedades modernas as trocas sociais são atravessadas pelo dinheiro e poder, como funcionariam os mecanismos de solidariedade? Por meio de ONGs, associações voluntárias, amigos, família e vizinhos. Um apoio social que está vinculado ao dom (dádiva), isto é, às práticas de sociabilidade que estão fora do mercado e do Estado e são feitas pelas redes de sociabilidade primária: família, amigos, vizinhos.

\section{CONSIDERAÇÕES FINAIS}

As redes sociais trazem em seu bojo o potencial para deflagrar inovações e ações transformadoras com impactos positivos na saúde de seus integrantes. A construção e a manutenção de redes que viabilizem colaboração, solidariedade, confiança e reconhecimento são fundamentais para saúde psíquica do trabalhador ${ }^{24}$.
Os tempos atuais exigem que o docente pense em rede como possibilidade de construir novas formas de convivência, baseadas na reciprocidade e na formação de alianças que garantam os direitos sociais dos envolvidos. Um “viver-junto" que contabilize saúde ao invés de solidão e de sofrimento.

Nas redes os objetivos, definidos coletivamente, articulam pessoas e instituições que se comprometem a superar de maneira integrada os problemas sociais. Estas redes são construídas entre seres sociais autônomos, que compartilham objetivos que orientam sua ação, respeitando a autonomia e as diferenças de cada membro (p. 39) 5 .

As redes sociais permitem a superação das determinações sociais - ação que exige ousadia, determinação e persistência dos atores. Experiências exitosas, como a da Universidade do Minho, inspiram-nos a ter esperança e seguir a contracorrente da lógica neoliberal que impera nas universidades. Projeto difícil, pois envolve resistências e riscos; exige coragem para mudar paradigmas e valores; exige reflexão, reconstrução e (inter)ação a fim de criar na universidade contemporânea um espaço de fala que inspire confiança e reciprocidade.

Tal postura requer a construção de redes que: possam tecer o "viver-junto"; integrem saberes e experiências; permitam um novo olhar para a realidade; sejam um espaço de negociação e formação de alianças; tenham análise compartilhada dos problemas; instalem novos valores (confiança, reciprocidade, tolerância às diferenças); criem novas formas de estar no mundo e no trabalho.

A ausência de suporte social fragiliza as pessoas. Investir nas redes sociais e no fortalecimento do capital social é uma ação preventiva e de promoção de saúde; é um projeto maior de uma universidade solidária, um espaço social de construção do conhecimento e de laços sociais geradores de saúde, interação, solidariedade, bem-estar e qualidade de vida.

O discurso dos docentes aponta no sentido de que a estrutura atual reinante nas universidades tem impactado negativamente na saúde do professor, pois tem minado a confiança e os laços entre eles. A criação de um sistema de dádiva nos colegiados será fundamental para o bem-estar e saúde dos professores.

\section{AGRADECIMENTOS}

À CAPES, que viabilizou meu estágio doutoral por seis meses na Universidade do Porto, e aos professores do Porto, Braga e Coimbra, que, apesar de seus inúmeros compromissos, disponibilizaram-se a construir comigo e com o Brasil mais uma rede de relacionamento. 


\section{REFERÊNCIAS}

1. Bourdieu P. O campo científico. In: Ortiz R, organizador. A sociologia de Pierre Bourdieu. São Paulo: Olho d’Água; 2003.

2. Bosi MLM. Pesquisa qualitativa em saúde coletiva: panorama e desafios. Cien Saude Colet. 2012;17(3):575-86. http://dx.doi.org/10.1590/S141381232012000300002. PMid:22450397.

3. Sato L, Lacaz FAC, Bernardo MH. Psicologia e saúde do trabalhador: práticas e investigações na Saúde Pública de São Paulo. Estud Psicol. 2006;11(3):281-8.

4. Paim JS. O objeto e a prática da Saúde Coletiva: o campo demanda um novo profissional? In: Anais do $1^{\circ}$ Seminário e Oficina de Trabalho "Graduação em Saúde Coletiva”: pertinência e possibilidades; 2002, set 5-6; Salvador. Salvador: ISC/UFBA; 2002. 12 p.

5. Junqueira LAP. Intersetorialidade, transetorialidade e redes sociais na saúde. RAP. 2000 nov-dez;34(6):35-45.

6. Gomide M, Barbosa JC, Heukelbach J, Ramos Jr AN. Rede social e rede básica de saúde: o papel formador da pesquisa operacional em hanseníase. Cad Saude Colet. 2009;17(1):103-14.

7. Santos JBF, Maciel RHMO, Sato L. Trabalhadores informais e a formação de redes socioprodutivas (RSP): considerações teórico-empiricas. Contemporanea. 2014;4(2):325-50.

8. Portugal S, Martins PH, organizadores. Cidadania, políticas públicas e redes sociais. Coimbra: Imprensa Universidade de Coimbra; 2011.

9. Bourdieu P. O capital social: notas provisórias. In: Nogueira MA, Catani A, organizadores. Escritos de educação. Petrópolis: Vozes; 1998. p. 67-9. [citado 2015 Jun 02]. Disponível em: http://pt.scribd.com/doc/110940422/ BOURDIEU-Pierre-Escritos-da-Educacao\#scribd

10. Costa R. Por um novo conceito de comunidade: redes sociais, comunidades pessoais, inteligência coletiva. Interface Comunicacao Saude Educ. 2005;9(17):235-48. http://dx.doi.org/10.1590/S1414-32832005000200003.

11. Vale GMV, Amâncio R, Lima JB. Criação e gestão de redes: uma estratégia competitiva para empresas e regiões. R. Adm. 2006;41(2):136-46.

12. Seixas AM. Políticas educativas e ensino superior em Portugal. Coimbra: Quarteto; 2003

13. Vieira F. Para uma mudança profunda da qualidade da pedagogia na universidade. REDU. 2014;12(2):23-39.
14. Dejours C, Bègue F. Suicídio e trabalho: o que fazer. Brasília: Paralelo 15; 2010.

15. Urbano CA. (id)entidade do ensino superior politécnico em Portugal: da Lei de Bases do sistema educativo à declaração de Bolonha. Sociologia Problemas e Práticas. 2011;66:95-115.

16. Vieira F. Reconfigurar a profissionalidade docente através de uma pedagogia da experiência. In: Actas do X Congresso Internacional Galego-Português de Psicopedagogia; 2009 set 9-11; Braga. Guimarães: Universidade do Minho; 2009. p. 5281-96.

17. Cabrito BG. O financiamento do ensino superior em Portugal: entre o Estado e o Mercado. Campinas Educ Soc. 2004;25(88):977-96. http:// dx.doi.org/10.1590/S0101-73302004000300016.

18. Minayo MCS. Análise qualitativa teoria, passos e fidedignidade. Cien Saude Colet. 2012;17(3):621-6. http://dx.doi.org/10.1590/S1413-81232012000300007. PMid:22450402.

19. Pope $C$, Mays N. Pesquisa qualitativa na atenção à saúde. Porto Alegre: Artmed; 2009.

20. Dejours C. Psicodinâmica do trabalho: contribuições da escola dejouriana à análise da relação prazer, sofrimento e trabalho. São Paulo: Atlas; 1994.

21. Portugal S. "As mãos que embalam o berço": um estudo sobre redes informais de apoio à maternidade. Rev Crit Cienc Soc. 1995;10(42):185-210. [citado 2015 Ago 12]. Disponível em: http://www.ces.uc.pt/publicacoes/rccs/ artigos/42/Silvia\%20Portugal\%20-\%20As\%20maos\%20que\%20embalam\%20 o\%20berco.pdf

22. Vieira F, Sá J, Morgado JC, Almeida J, Silva M. Representações da vida acadêmica: um estudo na Universidade do Minho. In: Actas do X Congresso Internacional Galego-Português de Psicopedagogia; 2009 set 9-11; Braga. Guimarães: Universidade do Minho; 2009. p. 5297-311.

23. Fontes BASM. Redes sociais e saúde mental. In: Portugal S, Martins PH, organizadores. Cidadania, políticas públicas e redes sociais. Coimbra: Imprensa Universidade de Coimbra; 2011. p. 105-12.

24. Tomaél MI, Alcará AR, Di Chiara IG. Das redes sociais à inovação. Cienc Inf. 2005;34(2):93-104. http://dx.doi.org/10.1590/S0100-19652005000200010.

Recebido em: Jun. 10, 2015 Aprovado em: Set. 08, 2015 